\title{
Efficacy of the Applied Natural Enemies on the Survival of Colorado Potato Beetle Adults
}

\author{
Vladimír Půža * Jiří Nermut', Jana Konopická ${ }^{\mathbb{D}}$ and Oxana Skoková Habuštová $\mathbb{D}$ \\ Biology Centre, Czech Academy of Sciences, Institute of Entomology, Branišovská 31, \\ 37005 České Budějovice, Czech Republic; Jirka.Nermut@seznam.cz (J.N.); jkonopicka@seznam.cz (J.K.); \\ habustova@entu.cas.cz (O.S.H.) \\ * Correspondence: vpuza@seznam.cz
}

check for updates

Citation: Půža, V.; Nermut', J.; Konopická, J.; Skoková Habuštová, O Efficacy of the Applied Natural Enemies on the Survival of Colorado Potato Beetle Adults. Insects 2021, 12, 1030. https://doi.org/10.3390/ insects12111030

Academic Editor: Zhenying Wang

Received: 25 October 2021

Accepted: 14 November 2021

Published: 16 November 2021

Publisher's Note: MDPI stays neutral with regard to jurisdictional claims in published maps and institutional affiliations.

Copyright: (c) 2021 by the authors. Licensee MDPI, Basel, Switzerland. This article is an open access article distributed under the terms and conditions of the Creative Commons Attribution (CC BY) license (https:/ / creativecommons.org/licenses/by/ $4.0 /)$.
Simple Summary: Colorado potato beetle (CPB) Leptinotarsa decemlineata is the potato plant's most destructive pest. Recently, resistance to the traditional insecticides has appeared, thus new environmentally friendly control agents are highly needed. In our study, we searched for the most effective entomopathogenic agents that could be used to decrease the emergence of CPB adults from the soil. We selected two entomopathogenic nematodes (Steinernema carpocapsae and S. feltiae) and one strain of fungus (Beauveria bassiana). The suspension application was done on the leaves, plus by watering the pods and the field plots. All the treatments had an obvious effect, but in the field, only the fungal treatment showed a promising result. Further research is needed to develop the most effective application for field usage.

Abstract: Colorado potato beetle Leptinotarsa decemlineata is among the most destructive pests of potatoes quickly developing resistance to traditional insecticides. In the present study, we tested the effect of various species and strains of entomopathogenic nematodes on CPB adults, and subsequently, the most effective nematodes were applied alone and in combination with entomopathogenic fungus B. bassiana in pots with potato plants and in the field and their effect on the number of emerging adults was evaluated. In the experimental infections, both the nematode invasion and pathogenicity were variable, and, in several strains, the mortality reached $100 \%$. In pot experiments, soil application of nematodes S. carpocapsae 1343 and S. feltiae Jakub and fungus significantly decreased numbers of emerging $\mathrm{CPB}$ adults, while, after the application on leaves, only fungal treatment was effective. The field application of fungus B. bassiana significantly decreased the number of emerging CPB adults in comparison to control sites by ca. 30\% while the effect of nematodes and the nematodes-fungus combination was not significant. In conclusion, we demonstrate the necessity of thorough bioassays to select the most effective nematode strains. Entomopathogenic nematodes have the potential to effectively decrease the emergence of $\mathrm{CPB}$ adults, but further research is needed to improve the effectiveness in the field.

Keywords: Colorado potato beetle; entomopathogenic nematodes; entomopathogenic fungi; Steinernema; Beauveria; field application

\section{Introduction}

Colorado potato beetle (CPB), Leptinotarsa decemlineata Say (Coleoptera: Chrysomelidae), is among the most destructive pests of potatoes (Solanum tuberosum L.). The adults and larvae feed on potato plants, significantly reducing the yield [1]. Since CPB is known to develop resistance to traditional insecticides [2-4], new environmentally safe control strategies are highly needed.

Entomopathogenic nematodes (EPNs) (Steinernematidae and Heterorhabditidae: Nematoda) are ubiquitous lethal insect parasites with global distribution and a wide host range [5]. Due to their ability to infect various insects [6], the possibility of mass production 
by industrial techniques [7], and their safety to non-target organisms and the environment $[8,9]$, EPNs represent an attractive agent for the biological control of many insect pests [10].

Entomopathogenic fungi (EPFs) represent other promising biocontrol agents. Their advantages are that they do not need to be ingested, as they are able to penetrate the host cuticle, and that they can be relatively easily produced [11]. The fungi are produced either in solid-state fermentation, where they produce aerial conidia, or in a submerged liquidstate fermentation, where they produce blastopores [12], and a number of mycoinsecticide, have been developed in the world [13].

In the last three decades, a considerable number of studies addressed the potential use of entomopathogenic nematodes for control of $\mathrm{CPB}$, but with variable results. Under laboratory conditions, Cantelo and Nickle [14] tested three EPN species at different dosage levels and achieved $100 \%$ mortality of CPB prepupae at a dose of 164.6 nematodes $/ \mathrm{cm}^{2}$. Similarly, Trdan et al. [15] have shown that four EPN species caused the prompt death of all CPB stages at doses of 200, 1000, and 2000 infective juveniles per individual in Petri dish experiments. So far only several field studies were performed. Nematode Heterorhabditis marelatus applied twice during the season caused a $50 \%$ reduction in adult CPB populations and produced six times as many dead prepupae in nematode-treated soil samples as in the untreated samples [16]. Recently, Čačija et al. [17] have demonstrated that S. feltiae and S. carpocapsae effectively decreased the number of overwintering CPB adults.

The effect of control agents can be increased by their combination $[18,19]$. The combined application of the nematode $S$. feltiae with entomopathogenic fungus Isaria fumosorosea significantly increased the CPB mortality in comparison to single-agent treatment [20]. Özdemir et al. [21] observed a synergistic effect between several chemical insecticides and S. feltiae against CPB. On the other hand, the negative effect of the combination has been recorded in the interactions between the EPN S. glaseri and fungus Metarhizium anisopliae [22] and between Steinernema ichnusae and B. bassiana fungus [23]. Therefore, the compatibility of control agents should be thoroughly tested before large-scale applications.

Colorado potato beetle adults are generally less susceptible to nematodes [16]. However, the reduction of pupating adults is desirable as it could decrease the damage caused by second-generation $\mathrm{CPB}$ in field conditions, as well as adult emergence in the next spring. Therefore in the present study, we focused on adult CPB and we tested a large number of EPN species and strains for pathogenicity to CPB adults in Petri dish assays in order to select the most effective nematodes. The selected nematodes were tested alone and in combination with entomopathogenic fungus in pot and field experiments. The combined application allows the testing of the hypothesis that the combination of the nematodes with $\mathrm{EPF}$ could increase the effectivity against $\mathrm{CPB}$.

\section{Materials and Methods}

\subsection{Culture of Colorado Potato Beetle}

The adults and larvae of Colorado potato beetle (CPB) were collected from the potato plants on an organic farm near the vicinity of Malonty village, Czech Republic (48.7083920 N; 14.5778508 E) in several consecutive series in July and August 2019-2021. Each developmental stage (larvae and adults) was collected separately inside a plastic box of size $34 \times 22.5 \times 15.7 \mathrm{~cm}$ with a perforated lid.

The collected culture of CPB was placed inside the fine mesh cage of size $100 \times 50 \times 50 \mathrm{~cm}$. Potato plants of the variety Magda, grown in a pot with a diameter of $21 \mathrm{~cm}$ and a volume of $4 \mathrm{~L}$, were provided for feeding. Culture was left in controlled greenhouse conditions $\left(25{ }^{\circ} \mathrm{C}, 75 \%\right.$ relative humidity and a long day photoperiod $\left.16: 8\right)$. Culture was checked daily and supplemented with fresh potato plants. Potato plants of the variety Magda were obtained in the form of tubers and tissue cultures (tiny plants) from the Potato Research Institute, Havlíčkův Brod. Plants were grown in a pot with a diameter of $21 \mathrm{~cm}$ and a volume of $4 \mathrm{~L}$, watered daily, and left in the same conditions as a CPB culture. The Magda 
variety is a dynamically growing plant with a big leaf and, therefore, is highly suitable for feeding.

\subsection{Rearing of Nematodes}

The nematodes used in this study either originated from the collection of the Laboratory of Entomopathogenic Nematodes, Biology Centre CAS, which contains both Czech and exotic EPN strains, or were obtained from the field sampling performed during this research (Table 1). In total, 32 EPN strains were used. Soil samples were collected in potato fields and field edges in 15 localities in Czech Republic in the years 2019 and 2020. At each sampling site, five samples of approximately $1 \mathrm{~kg}$ of soil were taken with a hand shovel to a depth of ca. $20 \mathrm{~cm}$. Each sample consisted of 10 subsamples from a ca. $100 \mathrm{~m}^{2}$ area. The modified Galleria baiting technique of Bedding and Akhurst [24] was used for EPN isolation. Four last-instar G. mellonella larvae were added to each sample. Samples were incubated for 5 days at $20{ }^{\circ} \mathrm{C}$ and at $55 \%$ relative humidity. Dead larvae were individually incubated in the White Traps (White, 1927). The infective juveniles (IJs) recovered from the traps were used both for molecular identification and the subsequent experiments. The nematode strains in the collection are maintained according to Kaya and Stock [25]. Before the experiments, all nematodes were propagated using G. mellonella, and 2-3-week-old IJs were used for the infections.

Table 1. Entomopathogenic nematodes used in different experiments. Marked strains $\left({ }^{*}\right)$ were isolated within this study, other strains originate in the laboratory collection.

\begin{tabular}{|c|c|c|c|}
\hline Species & Strain & Locality & Habitat \\
\hline S. kraussei, Oscheius onirici & $1 *, 1 b *$ & Dvorce, Lysá nad Labem & field edge \\
\hline S. affine & 4 * & Zubří, Nové Město n. M. & field \\
\hline S. feltiae & $6 *$ & Zubří, Nové Město n. M. & field \\
\hline S. feltiae & $7 *$ & Oupor, Obříství & field edge \\
\hline S. affine & $8 *$ & Havl. Borová & field \\
\hline S. feltiae & $15 *$ & Oupor, Obříství & field edge \\
\hline S. feltiae & $\mathrm{A} 2$ * & Malý Bor, Klatovy & field \\
\hline S. affine & $\mathrm{A} 3$ * & Dřevíkov, Chrudim & field edge \\
\hline S. affine & $\mathrm{A} 6$ * & Malý Bor, Klatovy & field edge \\
\hline S. feltiae & $\mathrm{A} 7$ * & Supíkovice & field edge \\
\hline S. kraussei & $\mathrm{A} 8$ * & Dřevíkov, Chrudim & field edge \\
\hline Rhabditis terricola & A9* & Chlebovice, Frýdek-Místek & field \\
\hline Diplogaster sp. & $\mathrm{A} 11$ * & Březová, Opava & field edge \\
\hline Diplogaster sp. & $\mathrm{A} 12$ * & Supíkovice & field edge \\
\hline S. affine & $\mathrm{A} 13$ * & Supíkovice & field \\
\hline S. affine & $\mathrm{A} 14 *$ & Valečov & field edge \\
\hline S. feltiae & Jakub * & Zbudov, Dívčice & field edge \\
\hline S. feltiae & $\mathrm{BM} 4$ * & Bojanovice & field edge \\
\hline S. feltiae & $\mathrm{BEM}$ * & Bělčice & field edge \\
\hline S. feltiae & $\mathrm{BP} 6$ * & Bělčice & field \\
\hline S. feltiae & $\mathrm{L} 2 *$ & Horažd'ovice & field edge \\
\hline S. feltiae & MP5 * & Malonty & field \\
\hline S. feltiae & MT2 * & Malonty & field \\
\hline S. feltiae & MT6* & Malonty & field \\
\hline H. bacteriophora & HB221 & Czech Republic & - \\
\hline S. arenarium & SLOV & Slovakia & - \\
\hline S. carpocapsae & 1343 & Czech Republic & - \\
\hline S. carpocapsae & Egy4 & Egypt & - \\
\hline S. carpocapsae & MG604 & Switzerland & - \\
\hline S. feltiae & 626 & Czech Republic & - \\
\hline S. feltiae & $37 \mathrm{Ca}$ & Canada & - \\
\hline S. feltiae & Bork & Czech Republic & - \\
\hline S. feltiae & Jakutsk & Russia & - \\
\hline S. feltiae & klen & Czech Republic & - \\
\hline S. feltiae & NFUST & Russia & - \\
\hline S. feltiae & Běl & Belarus & - \\
\hline S. kraussei & VČ1 & Czech Republic & - \\
\hline
\end{tabular}


Mass Rearing of Nematodes for Field Application

Nematodes for the field experiment were monoxenically mass produced in liquid medium by modified method according Stock and Goodrich-Blair [26] as follows. Gravid females of Steinernema feltiae, strain Jakub, were obtained by the dissection of Galleria mellonella larvae infected 4 days before dissection. Females (ca. 50 individuals) were placed in the $1.5 \mathrm{~mL}$ Eppendorf tubes with sterile tap water. Later, the water was removed, and females were gently crushed by a plastic microhomogenizer directly in the tube. Water was added $(1 \mathrm{~mL})$ to the homogenized females, and the tubes with females were centrifuged for $2 \mathrm{~min}$. at $2000 \mathrm{rpm}$. After this step, eggs were concentrated in the form of a small but clearly visible pellet on the bottom of the tubes. The supernatant was removed by pipet, and cleaning with water was repeated once again. After that, $1 \mathrm{~mL}$ of sterilization solution (10 mL tap water, $1.5 \mathrm{~mL} 4 \mathrm{M} \mathrm{NaOH}$, and $0.5 \mathrm{~mL} \mathrm{12 \%} \mathrm{NaOCl}$ ) was added. Eggs were incubated in this solution for $4 \mathrm{~min}$., and after that, the tubes were centrifuged for $2 \mathrm{~min}$. at $4000 \mathrm{rpm}$ to concentrate the eggs into a pellet again. The sterilization solution was removed and replaced by $1 \mathrm{~mL}$ of YS medium ( $5 \mathrm{~g}$ yeast extract, $5 \mathrm{~g} \mathrm{NaCl}, 0.5 \mathrm{~g} \mathrm{NH}_{4} \mathrm{H}_{2} \mathrm{PO}_{4}$, $0.5 \mathrm{~g} \mathrm{~K}_{2} \mathrm{HPO}_{4}, 0.2 \mathrm{~g} \mathrm{MgSO}_{4} \cdot 7 \mathrm{H}_{2} \mathrm{O}, 1 \mathrm{~L}$ distilled water), then centrifuged again for $2 \mathrm{~min}$. at $4000 \mathrm{rpm}$. This wash with YS medium was repeated twice. After that, sterile YS in a volume of $1 \mathrm{~mL}$ was added and the solution of medium with eggs was transferred to sterile multiwell plates ( 24 wells per plate), with $300 \mu \mathrm{L}$ of solution per one well. Plates were then sealed with parafilm and stored at $16^{\circ} \mathrm{C}$ for $72 \mathrm{~h}$ in a climatic box. If the solution was without any turbidity after that time, eggs or the hatched first stage larvae were considered sterile and axenic.

Symbiotic bacteria for the mass production of nematodes were obtained from Galleria mellonella larvae $24 \mathrm{~h}$ after infection with an appropriate nematode strain. Firstly, the infected larvae were washed in $70 \%$ ethanol and dried, and then one leg was cut by sterile scissors. A drop of hemolymph was placed on NBTA agar (37 $\mathrm{g}$ standard nutrient agar I, $25 \mathrm{mb}$ bromthymolblue, $4 \mathrm{~mL}$ 1\% 2,3,5,-triphenyl-tetracoliumcholoride) plate and dispersed on the surface of the plate; $90 \mathrm{~mm}$ Petri dishes with bacteria were sealed with parafilm and stored at room temperature, ca. $22{ }^{\circ} \mathrm{C}$. One day later, a single colony of the growing bacteria was transferred to the sterile YS medium $(20 \mathrm{~mL}$ of medium in a $50 \mathrm{~mL}$ Erlenmeyer flask) and cultivated with a shaker at $180 \mathrm{rpm}$ for 2 days. One $\mathrm{ml}$ of two-day-old culture was then used as inoculum for sterile nematode culture medium ( $50 \mathrm{~mL}$ of medium in a $250 \mathrm{~mL}$ Erlenmeyer flask), composed according to Dunn et al. [27]: $15 \mathrm{~g}$ yeast extract, $20 \mathrm{~g}$ soy powder, $4 \mathrm{~g} \mathrm{NaCl}, 0.35 \mathrm{~g} \mathrm{KCl}, 0.15 \mathrm{~g} \mathrm{CaCl}_{2}, 0.1 \mathrm{~g} \mathrm{MgSO}_{4}, 36 \mathrm{~mL}$ olive oil, and $1 \mathrm{~L}$ distilled water.).

Nematode culture medium inoculated with bacteria was shaken at $180 \mathrm{rpm}$ at $18{ }^{\circ} \mathrm{C}$ for $48 \mathrm{~h}$, and after that time, axenic nematode larvae were added to the flask. By this method, the established monoxenic culture was cultivated for 14 days at $18^{\circ} \mathrm{C}$ and $160 \mathrm{rpm}$. Within this time, the nematodes finished their life cycle and produced new IJs on a mass scale. These IJs were then used as inoculum for the subsequent mass production that was performed as described before. The nematode culture medium pre-inoculated with bacteria was settled with $1 \mathrm{~mL}$ of IJs obtained from the first cultivation. After 14 days, we collected nematodes for field applications and other experimental purposes. Nematodes were collected with the simple sedimentation method and by washing in tap water. All of the work regarding the cultivation of nematodes was done in strictly sterile conditions in a UV-sterilized flow box.

\subsection{Rearing of Entomopathogenic Fungus}

Beauveria bassiana strain BBA 08 was used in this study. The strain was isolated from the adult of the Colorado potato beetle (CPB), Leptinotarsa decemlineata, from the Bělčice site in the Czech Republic (49.50702 N; 13.89545 E). The strain was identified on the basis of macroscopic, microscopic, and genetic characteristics and has been deposited at the Biology Centre CAS, České Budějovice. The GenBank accession number of the LSU sequence is MN749315. 
Blastospores of the fungus BBA 08 were used in the experiments. The fungus was cultured in Potato Dextrose Broth liquid medium (Sigma-Aldrich, Darmstadt, Germany) at $25 \pm 1{ }^{\circ} \mathrm{C}$. For cultivation, $95 \mathrm{~mL}$ of liquid media was put into a $250 \mathrm{~mL}$ Erlenmeyer flask and inoculated with $5 \mathrm{~mL}$ of conidial fungus suspension. Then the flask was placed on an orbital shaker with a speed of $200 \mathrm{rpm}$ and temperature $25 \pm 1{ }^{\circ} \mathrm{C}$ for four days. After four days, the suspension was filtered through sterile gauze to separate the mycelium. In uniform suspension, the spores were counted with a Neubauer improved counting chamber (Sigma-Aldrich, Darmstadt, Germany), and subsequently, the suspension was adjusted to the required concentration.

The viability of spores was verified using a standard germination test [28]. Ten drops from suspension were applied using a $1 \mu \mathrm{L}$ inoculation loop on the surface of $2 \%$ water agar, which was poured in a thin layer onto the surface of a sterile slide. After the drops had dried, the slides were moved into a wet chamber and incubated at a temperature of $25 \pm 1{ }^{\circ} \mathrm{C}$ for $24 \mathrm{~h}$. The percentage of germinating spores was determined using an Olympus CH20 light microscope (Olympus Optical Co., Ltd., Tokyo, Japan); bright field, $400 \times$ magnification. The spore germination in all tests was $100 \%$.

\subsection{Petri Dish Infections}

In the experimental infections, the $\mathrm{CPB}$ adults were individually infected in Petri dishes $(9 \mathrm{~cm}$ diameter) lined with moist filter paper and a potato leaf for feeding. Various collection and freshly isolated EPN strains (Table 1) were applied at three doses of 250, 500, and 1000 IJs per one dish in a total water volume of $450 \mu \mathrm{L}$, each dose being applied in ten replicates. Control dishes received $450 \mu \mathrm{L}$ of water only, and there were ten control dishes for each nematode strain. The mortality of CPB was observed for 6 days and then both dead and live beetles were dissected in order to check for the presence of nematodes.

\subsection{Pot Experiments}

Pot experiments were designed to confirm the effectivity of the selected nematodes and the entomopathogenic fungus B. bassiana strain BBA 08 in outdoor conditions prior to the field application. Based on the Petri dish experiment, highly pathogenic strains S. feltiae strain Jakub and S. carpocapsae strain 1343 were selected. Some other strains displayed comparable, or even slightly higher pathogenicity, but we selected these Czech strains as they could be better adapted to local outdoor conditions.

The effects of both nematodes and fungus B. bassiana strain BBA 08 on pupating Colorado potato beetles in the soil and on CPB adults on plant leaves were tested in pots with potato plants (see above) in outdoor conditions, in České Budějovice, Czech Republic (48.9764494 N; 14.4473356 E).

Each combination was tested in 8 plastic pots (diameter $21 \mathrm{~cm}, 15 \mathrm{~cm}$ of organic soil) with one potato plant per pot $(25 \mathrm{~cm}$ high) that was populated with $5 \mathrm{IV}$. instar larvae or 5 adults of $L$. decemlineata prior to the application. Another four pots with either the IV. instar CPB larvae or adults were prepared as the control without bioagent application.

To assess the effect on pupating $\mathrm{CPB}$, both nematodes and fungus were applied to the soil by automatic pipette in $5 \mathrm{~mL}$ of water at a dose of 21,000 IJs for the nematodes and $1 \times 10^{9}$ for the fungus with nematode dosage corresponding to the standard recommended doses ( $5 \times 10^{5}$ IJs per square meter) and fungal dose corresponding to the half of the highest recommended dose for a commercial product based on B. bassiana BOTANIGARD $22 \mathrm{WP}\left(5.37 \times 10^{10} / \mathrm{m}^{2}\right)$. In the experiment with adults on leaves, the nematodes and fungus in the same dosage were sprayed on plant leaves. Each pot was closed into an entomological isolator to prevent adult beetles and larvae from escaping and also to protect them from natural enemies from the surrounding area.

The effect of leaf application was observed every day and after one week the final evaluation was done when all dead and live adults were counted. To evaluate the effect of soil application, the larvae were allowed to leave the leaves and move to the soil to 
pupate. Then the pots were observed daily and the numbers of emerging adult beetles were recorded.

\subsection{Field Application}

The field trial area was located near the village of Žabčice in the South Moravian Region (49.0219636 N; $16.6155681 \mathrm{E})$, in the corn production area, altitude $178 \mathrm{~m}$, average air temperature (1991-2020) $10.3{ }^{\circ} \mathrm{C}$, average total precipitation (1991-2020) $491.1 \mathrm{~mm}$. The surface is dominated by fluvial gley, and the soil type is a clayey loam. The pre-crop was spring barley. Our field was prepared with standard agrotechnical methods.

The total experimental area was $302.4 \mathrm{~m}^{2}$, which was divided into 12 experimental plots by using GPS navigation (Figure 1). One experimental plot $\left(25.2 \mathrm{~m}^{2}\right)$ contained 4 rows of potatoes, and the length of the row was $8.4 \mathrm{~m}$; the number of tubers in a row was 28 ; the distance between tubers in a row was $30 \mathrm{~cm}$, and the pitch was $0.75 \mathrm{~cm}$. The planted variety of potatoes was Rosara. Entomopathogenic nematode S. feltiae, strain Jakub, was selected as the more effective nematode from the pot experiments. The application of nematodes, fungus $B$. bassiana strain BBA 08 , their combination, and control was done shortly before the larvae of IV instar were ready to climb for pupation into the soil (larvae from the first generation of CPB adults). Each agent application was repeated in 3 repetitions.

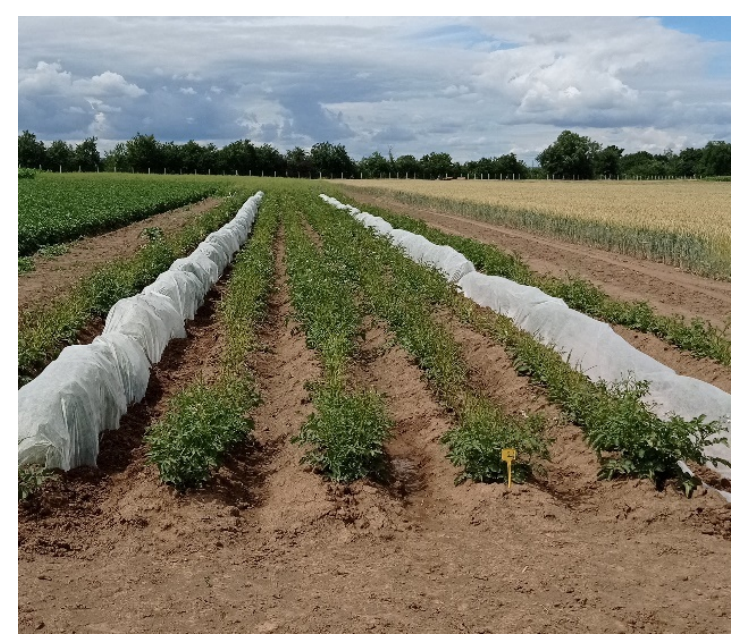

Figure 1. Experimental field with experimental rows covered with non-woven fabric.

The bioagents were applied at doses of 12.5 million IJs of EPN/plot/40 L of water, $1.72 \times 10^{11}$ spores of EPF/plot/40 L of water, and 12.5 million IJs of EPN $+1.72 \times 10^{11} \mathrm{EPF} / \mathrm{plot} / 40 \mathrm{~L}$. The nematode dose was derived from the recommended dose $\left(5 \times 10^{6} \mathrm{IJs}\right.$ per $\left.10 \mathrm{~m}^{2}\right)$ and the dose of EPF corresponded to ca. $12 \%$ of the highest recommended dose for the commercial product B. bassiana BOTANIGARD $22 \mathrm{WP}\left(5.37 \times 10^{10} / \mathrm{m}^{2}\right)$.

The control plots were watered by $40 \mathrm{~L}$ of water/plot. After application, two rows along the entire field trial were randomly selected, and treated plots were separately covered with non-woven fabric to prevent the leakage and mixing of CPBs (Figure 1). After 14 days, all second-generation CPB adults were counted. The occurrence was compared between treated plots with different bioagents and their combination to the control experiments.

\subsection{Statistical Analyses}

All statistical analyses were performed in Statistica version program 10, StatSoft Inc., Tulsa, OK, USA. Main effect ANOVA was used to analyze the data for invasion (numbers of invaded nematodes) and mortality in Petri dish experiments and for numbers of emerging beetles in the field experiment. One-way ANOVA was used to compare the numbers of emerging adults after soil application in the pot experiment and for the mortality data after leaf application and to compare invasion and mortality between endemic and non-endemic 
nematode strains. Tukey test was used to detect differences among individual treatments in the pot experiments. Prior to the analyses, count data (nematode invasion, numbers of emerging CPB adults) were square root transformed, and arcsin transformation was used for mortality data. In the text, the data are presented in the form of mean \pm SEM.

\section{Results}

\subsection{Field Sampling}

The sampling in the potato fields resulted in the isolation of 21 steinernematid strains (Table 1), out of which 13 strains belonged to $S$. feltiae, 6 strains were identified as $S$. affine, and 2 strains belonged to $S$. kraussei. The nematodes were present both on the field margins and within the fields.

\subsection{Petri Dish Infections}

During the dissections, we could observe that part of the nematodes were dead and encapsulated by CPB hemocytes. Nematodes were present also in the living insects, where dead nematodes prevailed. The proportion of dead nematodes also differed among nematode strains and the development to first-generation adults was observed only in some strains (data not shown). Mortality in control dishes was negligible.

In the experimental infections, both the nematode invasion and pathogenicity were quite variable (Figures 2 and 3), with strains with negligible invasion and negligible mortality (S. affine A14, S. kraussei 1) to strongly invasive and pathogenic strains (e.g., S. carpocapsae MG604). However, some strains with moderate invasion caused only a very low mortality (e.g., S. feltiae Jakutsk). Overall, there was no difference in invasion between endemic and non-endemic nematodes $(\mathrm{F}=0.404, p=0.527, \mathrm{df}=1)$ but non-endemic nematodes caused significantly higher mortality of CPB $(\mathrm{F}=6.396, p=0.013, \mathrm{df}=1)$.

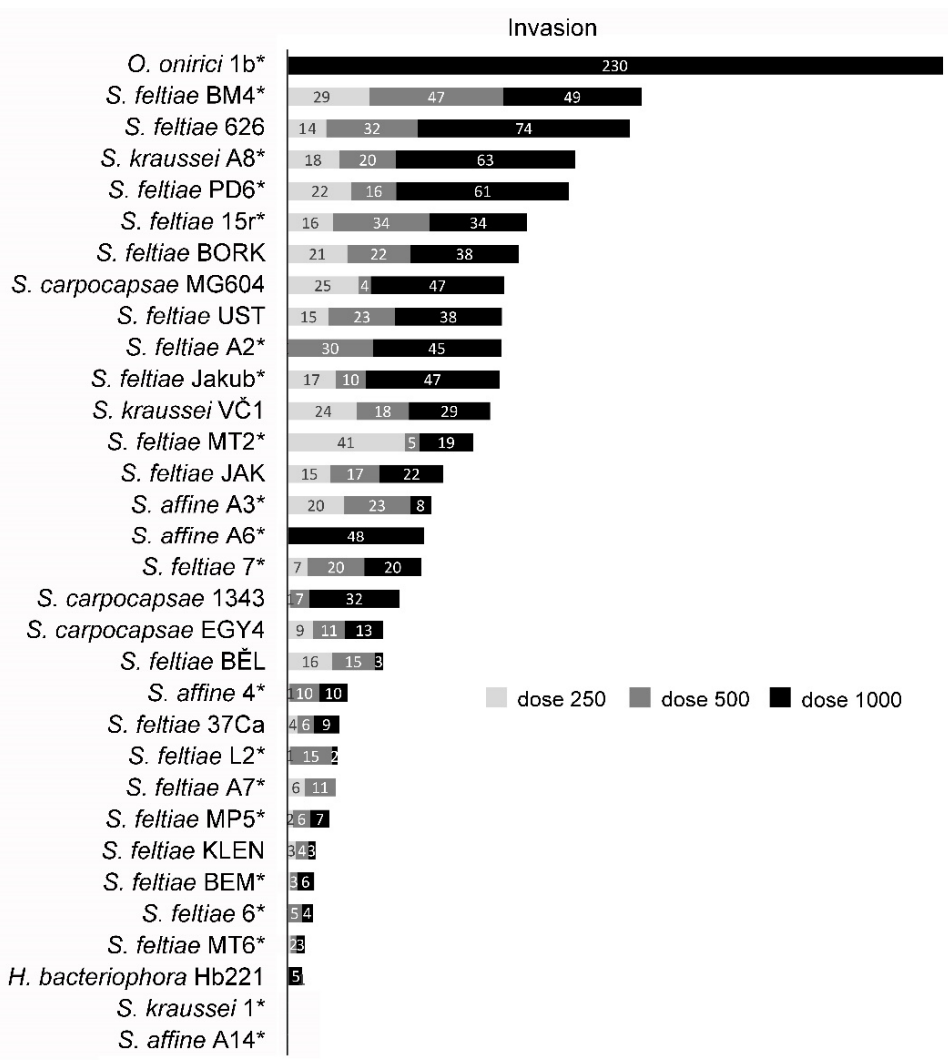

Figure 2. Mean numbers of nematodes of various EPN species and strains that invaded in adult Colorado potato beetles. The nematodes were applied at three doses of 250, 500, and 1000 IJs per host. Endemic strains isolated within this study are marked $\left(^{*}\right)$. 


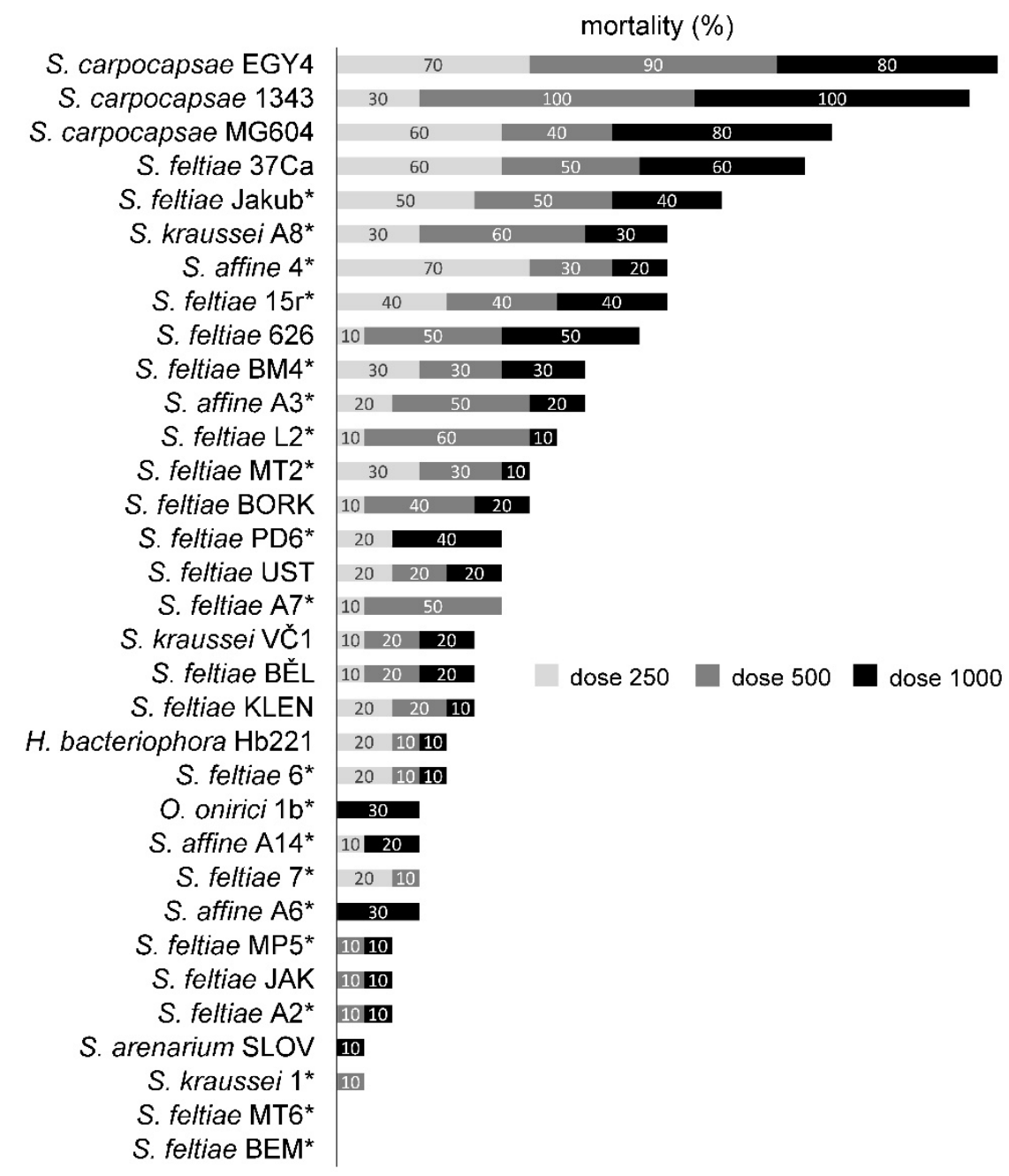

Figure 3. Percentage mortality of adult Colorado potato beetles caused by various EPN species and strains applied at three doses of 250, 500, and 1000 IJs per host. Endemic strains isolated within this study are marked $\left(^{*}\right)$.

In general, $S$. carpocapsae strains had consistently moderate to high invasion and caused the highest CPB mortality reaching $100 \%$ in higher doses of S. carpocapsae strain 1343. Performance of $S$. feltiae and S. kraussei strains was variable, and the highest mortality, reaching 50\% in all doses, was observed in S. feltiae 37Ca and S. feltiae Jakub, with the latter showing a higher invasion. The invasiveness and pathogenicity of $S$. affine strains and the only heterorhabditid strain, Heterorhabditis bacteriophora $\mathrm{Hb} 221$, were lower. The facultatively parasitic nematode Oscheius onirici caused CPB mortality only at the highest dose, and its invasion was very high, but occurred only in the dead beetles.

Based on these results, two EPN strains, S. carpocapsae 1343 and S. feltiae Jakub, were selected for further experiments.

\subsection{Pot Experiments}

Soil application of both nematodes (S. carpocapsae 1343 and S. feltiae Jakub) and fungus resulted in a significant decrease in the number of emerging CPB adults in comparison to control ( $\mathrm{df}=3,28, \mathrm{~F}=31.9, p<0.001$ ). As visible in the graph (Figure $4 \mathrm{a}$ ), both nematode strains and fungus caused significantly higher mortality than was observed in control $(p<0.05)$. Beauveria bassiana and S. feltiae Jakub have significantly $(p<0.05)$ higher mortality (more than 80\%) than S. carpocapsae 1343 (less than $40 \%$ ). 

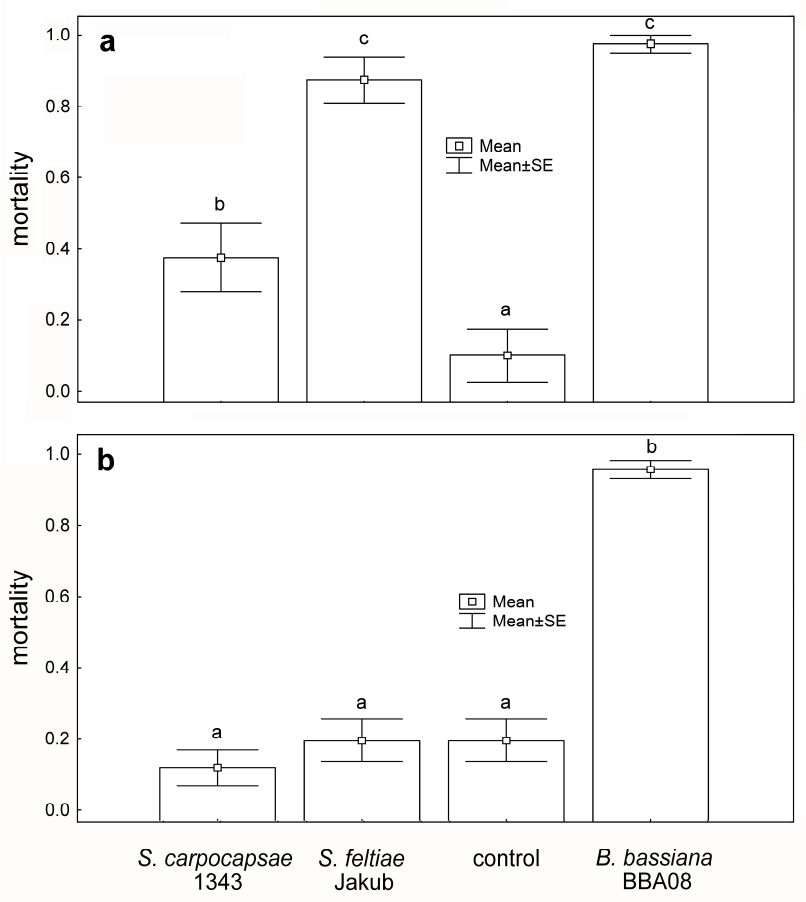

Figure 4. Mortality of pupating CPB in the soil (a) and adults on the potato leaves (b) after the application of entomopathogenic nematodes and fungus. Different letters above bars indicate statistically significant differences.

After the application of nematodes on the leaves against adults of $L$. decemlineata, the observed mortality was not significantly different from control and reached a maximum of around $20 \%$ or lower (Figure $4 \mathrm{~b})$. On the other hand, the leaf application of fungus ( $\mathrm{df}=3$, $28, \mathrm{~F}=37.5, p<0.001$ ) was very successful, reaching mortality higher than $90 \%$.

\subsection{Field Application}

In the field experiment, statistical analyses revealed significant differences among treatments $(\mathrm{F}=3.15, p=0.025, \mathrm{df}=3)$, but only the application of fungus $B$. bassiana significantly decreased the number of emerging $\mathrm{CPB}$ adults in comparison to control sites, by ca. $30 \%(p=0.014)$ with a mean number of CPB adults emerged per 1 potato plant of $25.9 \pm 2.84$ vs. $35.7 \pm 3.43$ in control plots. The number of emerging adults from the sites with the application of $S$. feltiae strain Jakub $(29.6 \pm 3.24)$ and its combination with fungus B. bassiana (29.6 \pm 2.12$)$ were around $20 \%$ lower in comparison to control $(35.7 \pm 3.43)$, though the difference was not statistically significant $(p=0.014)$.

\section{Discussion}

Endemic EPN strains can be more effective against target pests than exotic ones [29,30], and, therefore, we performed the sampling in the target localities. Interestingly, we recorded a massive presence and diversity of EPNs in Czech potato fields. Entomopathogenic nematodes are ubiquitous soil organisms; however, in general, their occurrence in the agroecosystems tends to be low [31]. In the light of this fact, our results are surprising, and it can be assumed that, in Czech fields, naturally occurring EPNs could contribute to the regulation of $\mathrm{CPB}$ populations.

The ubiquity of $S$. feltiae and to a lesser extent $S$. affine is not surprising, as the former species is the most common EPN in the Czech Republic and the latter is frequent in the agroecosystems [32]; on the other hand, the isolation of two strains of S. kraussei is surprising, as it represents the first finding of this species in arable areas of the Czech Republic [32]. The isolation of Oscheius onirici is the first finding of this nematode in the Czech Republic. 
Our experimental infections with endemic and non-endemic strains did not support the superiority of endemic strains, but conversely, non-endemic EPN strains were generally more pathogenic. In accordance with our results, Berry et al. [33] observed exotic EPN strains being superior to endemic ones in CPB infections.

Overall, the experimental infections have shown considerable variability both in the invasion and pathogenicity of the nematodes tested. Inter and intraspecific differences in EPN infectivity towards different hosts are well known (e.g., [34]), and in this particular case, the differences could be related to host immune response. The Colorado potato beetle is known to possess an effective immunity response towards EPNs via encapsulation [35]. Accordingly, during dissections, we often observed dead IJs or even adults encapsulated by CPB hemocytes. Different insects have been shown to differ in their immune reaction towards different EPN species [36]; it can be hypothesized that the high effectivity of S. carpocapsae strains could be due to the lower immune response of the host. The high variability in the performance of nematode species and strains highlights the importance of thorough screening in the search for suitable biocontrol agents for CPB control.

With a majority of the tested strains killing only ca. 30\% of CPB adults or less, even at the highest dose of 1000 IJs per beetle, the mortality is quite low in comparison with published data from infections of CPB prepupal stages [20,33], but CPB adults are known to be less susceptible than prepupal stages [16]. Trdan et al. [15] reported the lowest LC50 for adult CPB infections being 463 IJs / adult in S. carpocapsae, while in the present study, a mortality of well over $50 \%$ was achieved with $S$. carpocapsae strains even at the lowest dose of 250 IJs per one CPB adult.

Field applications of biocontrol agents tend to be less successful due to uncontrolled abiotic and biotic factors. The results of the field application of the nematodes, fungus, and their combination with only the fungus causing a significant decrease in comparison to untreated control are not surprising. The rate of infestation in the experimental field was very high, with more than 200 adult beetles emerging from under a canopy of a single plant, so possibly the standard doses of bioagents were too low to cause considerable effect. In comparison to similar studies, the $20 \%$ decrease of the CPB population in S. feltiae-treated sites in our study was lower than the $31 \%$ reduction of the late-season adults of the CPB treated with $S$. carpocapsae at a little higher dosage $\left(7.6 \times 10^{5}\right.$ per $\mathrm{m}^{2}$ vs. $5 \times 10^{5}$ per $\left.\mathrm{m}^{2}\right)$ [37]. Caged small plots with potatoes treated with S. feltiae and H. heliothidis (later synonymized with $H$. bacteriophora) decreased the emergence of CPB adults by 66-77\% [38], but the dose of 90-150 IJs per $\mathrm{cm}^{2}$ was two to three times higher than in the present study.

Interestingly, in our experiment, the combination of both bioagents had a worse result than fungus alone. Interactions between some bioagents can be antagonistic [39], and, similar to our result, Shapiro-Ilan et al. [40] observed that, when pairs of nematode and fungal pathogens attacked weevils of Curculio caryae, most pairings were less effective than a single highly effective entomopathogenic species. The negative effect of entomopathogenic fungi on EPNs has been described on several occasions. The development of Steinernema feltiae was negatively affected when the nematode was applied on Colorado potato beetle larvae $24 \mathrm{~h}$ or later after fungus I. fumosorosea [20]. A similar negative effect on nematode growth was observed in the interactions between the EPF Metarhizium anisopliae and EPNs Steinernema glaseri [22] and H. bacteriophora [41]. On the other hand, in our study, the combined application showed worse results in comparison to fungus alone, which would suggest a negative effect of the nematode on fungus performance. The secondary metabolites of the nematode bacterial symbionts of the genus Xenorhabdus produce many bioactive compounds, including fungistatic substances [42], and a negative effect of some of these metabolites on the growth of the fungus B. bassiana were observed [23]. Coinfections of CPB adults in the locality thus could reduce the reproduction of the fungus, leading to lower overall CPB mortality. Further research is needed to shed more light on the interactions of these particular biocontrol agents. Nevertheless, our present results do not allow us to recommend the combination of the nematodes and B. bassiana in the field. 
Pupating summer generation CPB adults spend only several weeks in the soil, and thus the time that biocontrol agents have to localize and infect pupating insects is limited. Our further research will focus on overwintering CPB generation, where the nematodes and fungi can operate for a long period.

\section{Conclusions}

In conclusion, we demonstrate that, due to the high variability in nematode pathogenicity towards CPB adults, large-scale screening is necessary in order to select the effective nematode strains. The selected nematodes and fungus $B$. bassiana effectively decreased the emergence of second-generation CPB adults in pots, while the effect of the field application of both agents and their combination was low. Further research will focus on overwintering CPB generation.

Author Contributions: Conceptualization, V.P., J.N., J.K. and O.S.H.; methodology, V.P., J.N., J.K. and O.S.H.; software, V.P.; validation, V.P., J.K., J.N. and O.S.H.; formal analysis, V.P., J.K. and O.S.H.; investigation, V.P., J.N., J.K. and O.S.H.; resources, V.P. and J.K.; data curation, V.P.; writingoriginal draft preparation, V.P.; writing—-review and editing, J.N., J.K., and O.S.H.; visualization, V.P.; supervision, V.P. and J.N.; project administration, O.S.H.; funding acquisition, O.S.H. All authors have read and agreed to the published version of the manuscript.

Funding: This research was funded by National Agency for Agricultural Research (NAZV) Project No. QK1910270. Additional support was obtained from the Czech Academy of Sciences (RVO:60077344) and from the Operational Program Integrated Infrastructure (OPII) within the project sustainable smart farming systems taking into account the future challenges, Project No. (ITMS 313011W112), co-financed by the European Regional Development Fund.

Institutional Review Board Statement: Not applicable.

Informed Consent Statement: Not applicable.

Data Availability Statement: Not applicable.

Acknowledgments: The authors are grateful to Daniela Hlávková and Radka Tanzer Fabiánová for technical assistance.

Conflicts of Interest: The authors declare no conflict of interest.

\section{References}

1. James, C. Global Status of Commercialized Biotech/GM Crops, 2011; ISAAA: Ithaca, NY, USA, 2011; Volume 44.

2. Grafius, E. Economic Impact of Insecticide Resistance in the Colorado Potato Beetle (Coleoptera: Chrysomelidae) on the Michigan Potato Industry. J. Econ. Entomol. 1997, 90, 1144-1151. [CrossRef]

3. Cutler, G.C.; Tolman, J.H.; Scott-Dupree, C.D.; Harris, C.R. Resistance Potential of Colorado Potato Beetle (C4) to Novaluron. J. Econ. Entomol. 2005, 98, 1685-1693. [CrossRef]

4. Alyokhin, A.; Baker, M.; Mota-Sanchez, D.; Dively, G.; Grafius, E. Colorado Potato Beetle Resistance to Insecticides. Am. J. Potato Res. 2008, 85, 395-413. [CrossRef]

5. Poinar, G.O. Nematodes for Biological Control of Insects; CRC Press: Boca Raton, FL, USA, 2018; ISBN 1-351-08340-6.

6. Laumond, C.; Mauléon, H.; Kermarrec, A. Données Nouvelles Sur Le Spectre d'hôtes et Le Parasitisme Du Nématode Entomophage Neoaplectana carpocapsae. Entomophaga 1979, 24, 13-27. [CrossRef]

7. Woodring, J.L.; Kaya, H.K. Steinernematid and Heterorhabditid Nematodes: A Handbook of Biology and Techniques. South. Coop. Ser. Bull. (USA) 1988, 331, 30.

8. Bathon, H. Impact of Entomopathogenic Nematodes on Non-Target Hosts. Biocontrol Sci. Technol. 1996, 6, 421-434. [CrossRef]

9. Ehlers, R.-U.; Hokkanen, H. Insect Biocontrol with Non-Endemic Entomopathogenic Nematodes (Steinernema and Heterorhabditis spp.): Conclusions and Recommendations of a Combined OECD and COST Workshop on Scientific and Regulatory Policy Issues. Biocontrol Sci. Technol. 1996, 6, 295-302. [CrossRef]

10. Půža, V. Control of insect pests by entomopathogenic nematodes. In Principles of Plant-Microbe Interactions; Springer: Berlin/Heidelberg, Germany, 2015; pp. 175-183.

11. Inglis, D.M.; Goettel, M.S.; Butt, T.M.; Strasser, H. Use of hyphomycetous fungi for managing insect pests. In Fungi as Biocontrol Agents: Progress Problems and Potential; CABI: Wallingford, UK, 2001; p. 23.

12. Jackson, M.A.; Dunlap, C.A.; Jaronski, S.T. Ecological Considerations in Producing and Formulating Fungal Entomopathogens for Use in Insect Biocontrol. BioControl 2010, 55, 129-145. [CrossRef] 
13. de Faria, M.R.; Wraight, S.P. Mycoinsecticides and Mycoacaricides: A Comprehensive List with Worldwide Coverage and International Classification of Formulation Types. Biol. Control 2007, 43, 237-256. [CrossRef]

14. Cantelo, W.W.; Nickle, W.R. Susceptibility of Prepupae of the Colorado Potato Beetle (Coleoptera: Chrysomelidae) to Entomopathogenic Nematodes (Rhabditida: Steinernematidae, Heterorhabditidae). J. Entomol. Sci. 1992, 27, 37-43. [CrossRef]

15. Trdan, S.; Vidrih, M.; Andjus, L.; Laznik, Ž. Activity of Four Entomopathogenic Nematode Species against Different Developmental Stages of Colorado Potato Beetle, Leptinotarsa decemlineata (Coleoptera, Chrysomelidae). Helminthologia 2009, 46, 14-20. [CrossRef]

16. Armer, C.A.; Berry, R.E.; Reed, G.L.; Jepsen, S.J. Colorado Potato Beetle Control by Application of the Entomopathogenic Nematode Heterorhabditis marelata and Potato Plant Alkaloid Manipulation. Entomol. Exp. Appl. 2004, 111, 47-58. [CrossRef]

17. Čačija, M.; Bažok, R.; Kolenc, M.; Bujas, T.; Drmić, Z.; Kadoić Balaško, M. Field Efficacy of Steinernema sp. (Rhabditida: Steinernematidae) on the Colorado Potato Beetle Overwintering Generation. Plants 2021, 10, 1464. [CrossRef]

18. Guetsky, R.; Shtienberg, D.; Elad, Y.; Dinoor, A. Combining Biocontrol Agents to Reduce the Variability of Biological Control. Phytopathology 2001, 91, 621-627. [CrossRef]

19. Otsuki, H.; Yano, S. Functionally Different Predators Break down Antipredator Defenses of Spider Mites. Entomol. Exp. Appl. 2014, 151, 27-33. [CrossRef]

20. Hussein, H.M.; Skoková Habuštová, O.; Půža, V.; Zemek, R. Laboratory Evaluation of Isaria fumosorosea CCM 8367 and Steinernema feltiae Ustinov against Immature Stages of the Colorado Potato Beetle. PLoS ONE 2016, 11, e0152399. [CrossRef]

21. Özdemir, E.; İnak, E.; Evlice, E.; Yüksel, E.; Delialioğlu, R.A.; Susurluk, I.A. Effects of Insecticides and Synergistic Chemicals on the Efficacy of the Entomopathogenic Nematode Steinernema feltiae (Rhabditida: Steinernematidae) against Leptinotarsa decemlineata (Coleoptera: Chrysomelidae). Crop Prot. 2021, 144, 105605. [CrossRef]

22. Ansari, M.; Tirry, L.; Moens, M. Interaction between Metarhizium anisopliae CLO 53 and Entomopathogenic Nematodes for the Control of Hoplia philanthus. Biol. Control 2004, 31, 172-180. [CrossRef]

23. Tarasco, E.; Santiago Alvarez, C.; Triggiani, O.; Quesada Moraga, E. Laboratory Studies on the Competition for Insect Haemocoel between Beauveria bassiana and Steinernema ichnusae Recovered in the Same Ecological Niche. Biocontrol Sci. Technol. 2011, 21, 693-704. [CrossRef]

24. Bedding, R.; Akhurst, R. A Simple Technique for the Detection of Insect Parasitic Rhabditid Nematodes in Soil. Nematology 1975, 21, 109-110. [CrossRef]

25. Kaya, H.K.; Stock, S.P. Techniques in insect nematology. In Manual of Techniques in Insect Pathology; Elsevier: Amsterdam, The Netherlands, 1997; pp. 281-324.

26. Stock, S.P.; Goodrich-Blair, H. Nematode Parasites, Pathogens and Associates of Insects and Invertebrates of Economic Importance. Man. Tech. Invertebr. Pathol. 2012, 2, 375-425.

27. Dunn, M.D.; Belur, P.D.; Malan, A.P. In Vitro Liquid Culture and Optimization of Steinernema jeffreyense Using Shake Flasks. BioControl 2020, 65, 223-233. [CrossRef]

28. Skalický, A.; Bohatá, A.; Šimková, J.; Osborne, L.S.; Landa, Z. Selection of Indigenous Isolates of Entomopathogenic Soil Fungus Metarhizium Anisopliae under Laboratory Conditions. Folia Microbiol. 2014, 59, 269-276. [CrossRef]

29. Mráček, Z.; Bečvár, S.; Kindlmann, P.; Webster, J. Infectivity and Specificity of Canadian and Czech Isolates of Steinernema kraussei (Steiner, 1923) to Some Insect Pests at Low Temperatures in the Laboratory. Nematologica 1998, 44, 437-448.

30. Matuska-Łyżwa, J. Ecological and Morphological Characteristics of Steinernema kraussei (Rhabditida: Steinernematidae): Comparison of Nematodes Isolated from the Natural Environments and Originated from the Commercial Pesticide. Ecol. Quest. 2014, 19, 51-55. [CrossRef]

31. Campos-Herrera, R.; Gomez-Ros, J.M.; Escuer, M.; Cuadra, L.; Barrios, L.; Gutiérrez, C. Diversity, Occurrence, and Life Characteristics of Natural Entomopathogenic Nematode Populations from La Rioja (Northern Spain) under Different Agricultural Management and Their Relationships with Soil Factors. Soil Biol. Biochem. 2008, 40, 1474-1484. [CrossRef]

32. Půža, V.; Nermut', J. Entomopathogenic nematodes in the Czech Republic: Diversity, occurrence and habitat preferences. In Nematode Pathogenesis of Insects and Other Pests; Springer: Berlin/Heidelberg, Germany, 2015; pp. 421-429.

33. Berry, R.; Liu, J.; Reed, G. Comparison of Endemic and Exotic Entomopathogenic Nematode Species for Control of Colorado Potato Beetle (Coleoptera: Chrysomelidae). J. Econ. Entomol. 1997, 90, 1528-1533. [CrossRef] [PubMed]

34. Bedding, R.; Molyneux, A.; Akhurst, R. Heterorhabditis spp., Neoaplectana spp., and Steinernema kraussei: Interspecific and Intraspecific Differences in Infectivity for Insects. Exp. Parasitol. 1983, 55, 249-257. [CrossRef]

35. Thurston, G.S.; Yule, W.; Dunphy, G. Explanations for the Low Susceptibility of Leptinotarsa decemlineata to Steinernema carpocapsae. Biol. Control 1994, 4, 53-58. [CrossRef]

36. Li, X.-Y.; Cowles, R.; Cowles, E.; Gaugler, R.; Cox-Foster, D. Relationship between the Successful Infection by Entomopathogenic Nematodes and the Host Immune Response. Int. J. Parasitol. 2007, 37, 365-374. [CrossRef] [PubMed]

37. Stewart, J.G.; Boiteau, G.; Kimpinski, J. Management of Late-Season Adults of the Colorado Potato Beetle (Coleoptera: Chrysomelidae) with Entomopathogenic Nematodes. Can. Entomol. 1998, 130, 509-514. [CrossRef]

38. Wright, R.J.; Agudelo-Silva, F.; Georgis, R. Soil Applications of Steinernematid and Heterorhabditid Nematodes for Control of Colorado Potato Beetles, Leptinotarsa Decemlineata (Say). J. Nematol. 1987, 19, 201. [PubMed] 
39. Hummadi, E.H.; Dearden, A.; Generalovic, T.; Clunie, B.; Harrott, A.; Cetin, Y.; Demirbek, M.; Khoja, S.; Eastwood, D.; Dudley, E. Volatile Organic Compounds of Metarhizium brunneum Influence the Efficacy of Entomopathogenic Nematodes in Insect Control. Biol. Control 2021, 155, 104527. [CrossRef] [PubMed]

40. Shapiro-Ilan, D.I.; Jackson, M.; Reilly, C.C.; Hotchkiss, M.W. Effects of Combining an Entomopathogenic Fungi or Bacterium with Entomopathogenic Nematodes on Mortality of Curculio caryae (Coleoptera: Curculionidae). Biol. Control 2004, 30, 119-126. [CrossRef]

41. Acevedo, J.P.M.; Samuels, R.I.; Machado, I.R.; Dolinski, C. Interactions between Isolates of the Entomopathogenic Fungus Metarhizium anisopliae and the Entomopathogenic Nematode Heterorhabditis bacteriophora JPM4 during Infection of the Sugar Cane Borer Diatraea saccharalis (Lepidoptera: Pyralidae). J. Invertebr. Pathol. 2007, 96, 187-192. [CrossRef] [PubMed]

42. Tobias, N.J.; Shi, Y.-M.; Bode, H.B. Refining the Natural Product Repertoire in Entomopathogenic Bacteria. Trends Microbiol. 2018, 26, 833-840. [CrossRef] [PubMed] 